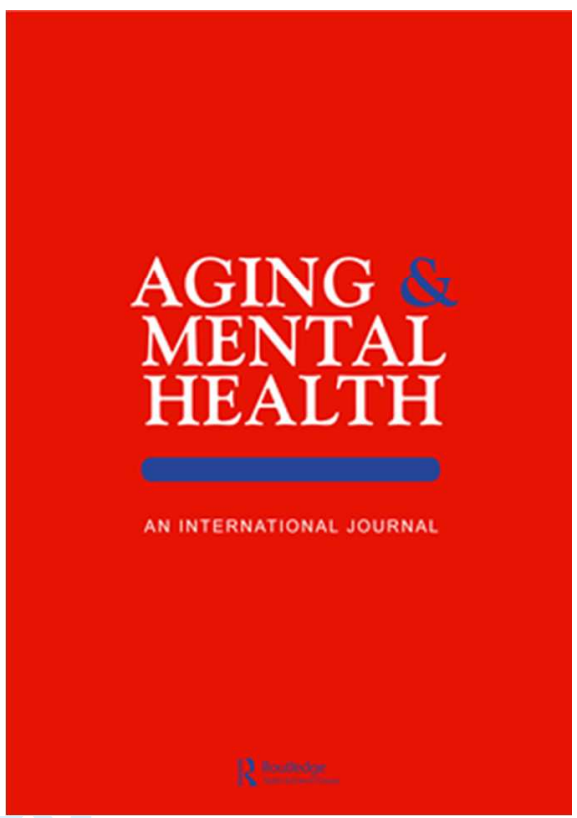

\title{
Social and Functional Health of Home Care Clients with Different Levels of Cognitive Impairments
}

\begin{tabular}{|r|l|}
\hline Journal: & Aging and Mental Health \\
\hline Manuscript ID & CAMH-2016-0239 \\
\hline Manuscript Type: & Original Article \\
\hline Keywords: & $\begin{array}{l}\text { social health, cognitive performance, home care clients, everyday coping, } \\
\text { interRAI assessment }\end{array}$ \\
\hline
\end{tabular}

\section{SCHOLARONE"}

Manuscripts 
Running Head: SOCIAL HEALTH AND COGNITIVE PERFORMANCE 1

\begin{abstract}

\section{Objectives}

According to Huber and colleagues (2011: 2), the ability of "managing own life with some degree of independence", "fulfilling of basic obligations", and "participating in social activities" are social functions that delineate the core of "social health". We examine to what extent clients of community care in Europe $(n=2796)$ are able to complete such activities despite the fact that many of them exhibit cognitive problems. Here, we focus particularly on "mildly and moderately impaired people", age 65 years and older.
\end{abstract}

\title{
Methods
}

Data were collected using the interRAI HC-Assessment in the framework of the IBenC-project. We tested the association between participants' capacity and performance in three IADLs and their general cognitive performance and specific memory problems using a general linear model.

\section{Results}

About thirty percent of clients of community home care services in Europe suffer from mild to moderate cognitive impairment. Their relatively independent coping with requirements of routine activities at home and in the community is strongly determined by overall cognitive performance. Specific memory functions are relatively unimportant, except for procedural memory. In terms of social relations, it is striking that all clients, and particularly those with mild to moderate cognitive impairment interact mostly with close relatives and friends.

\section{Discussion}


Running Head: SOCIAL HEALTH AND COGNITIVE PERFORMANCE 2

\author{
When considering the influence of cognitive function on clients' capacity and \\ performance in everyday activities and social relations, a comprehensive construct of \\ cognitive function has to be applied; specific subdomains, for example, relatively narrow \\ realms of memory seem to have a limited influence when examined on their own.
}

Keywords: social health; cognitive performance; home care clients; everyday coping; interRAI assessment 


\section{Running Head: SOCIAL HEALTH AND COGNITIVE PERFORMANCE 3}

\section{Background and Aims}

The concept of ICF (WHO, 2001) has radically changed how we view people with disabilities and chronic health problems (Garms-Homolová et al., 2009). This view focuses increasingly on the prospects of participation even of individuals with considerable cognitive and intellectual disabilities (WHO, 2013, p.116ff). Their competence "to manage their lives with some degree of independence", "to fulfill their basic obligations" and "to participate in social activities" delineate the core of the definition of "Social Health" (Huber et al., 2011, p. 2). The authors stress how important a successful adaptation to illness or personal functional limitations is, and report about an extensive learning of daily life management despite chronic illness. In our contribution, we consider people with cognitive problems, such as loss of ability to make even simple decision independently or with major memory problems. Obviously, these disabilities make adaptation, reorientation, and "learning of new coping behavior" (Boote, et al., 2006) extremely difficult (Caffò et al.,2012). Practitioners working with cognitively impaired people and with people suffering from dementia often state that these individuals continue to live in their "primary" world, where their behavior is meaningful (Kruse, 2005). However, in the light of expectations and requirements of the "general society", this behavior can be interpreted as disability overly hastily. Some concepts of dementia care show that people affected by cognitive losses need an appropriate physical and social environment (Day et al., 2000). If it is available, fewer coping problems occur.

Our research targets older clients receiving home care in communities of six European countries $(n=2796)$. It has been conducted within the IBenC-project (Identifying best practices for care-dependent elderly by BENchmarking costs and outcomes of community Care) in the $7^{\text {th }}$ framework of the European Commission. Regularly, physical and /or cognitive, or psychological impairments are prerequisites for eligibility for care provision (Genet, et al., 2012). Research has shown that professional caregivers are still better qualified for care of people with somatic diseases and physical disabilities than of individuals with cognitive 
Running Head: SOCIAL HEALTH AND COGNITIVE PERFORMANCE 4

problems (Garms-Homolová et al., 2012). Additionally, the time for home care by professionals is often limited (Garms-Homolová, 2013). It is uncertain whether the clients can cope in the way that is possible for them.

In our analysis we focus on home care clients with a mild or moderate cognitive impairment. We assume that this status is probably not an insurmountable obstacle for the fulfillment of the requirements of everyday life. We expect that these clients still manage some tasks like payment of bills, taking medication, and use of the phone. At the same time, we consider these tasks as cognitively challenging (Morris et al., 2015). The same applies to some social obligations, e.g., participation in accustomed social activities, reciprocal visits with family members, friends, or other significant confidants as well as to keeping contact by phone or email. They are also examined in this contribution.

\section{Method}

We used data from 2,796 home care clients who underwent a standardized geriatric assessment (interRAI HC - see www.interRAI.org) and two reassessments after six months and one year, respectively. In this paper, the first reassessment was considered. Only individuals who were 65 years of age and older and those who received the services for at least 14 days were included in the study. The future prospects of the clients had a decisive meaning for the sampling. Not included into the study were clients in the end stage of their life or those whose relocation to a nursing home or ending of the care provision were imminent. The interRAI HC assessment is a standardized and fully structured geriatric instrument with about 320 variables divided into 19 sections. The health status of the person as well as the health problems are covered comprehensively. In this way, particularly "functional health" (physical, cognitive, social capabilities and behavior) can be assessed comprehensively. Basic information on demography, living arrangement, and living environment is also included. Four sections are dedicated to the provision of health care. 


\section{Running Head: SOCIAL HEALTH AND COGNITIVE PERFORMANCE 5}

The assessments were carried out by professional nurses who provided the normal, everyday care. In some countries "routine data" were used. To ensure a good quality of data, a special training was offered to this staff. Additionally, research nurses were available to support the nurses during the process of data collection.

We measured cognitive status using the CPS (Cognitive Performance Scale, Morris et al., 1994, Hartmeier et al., 1995) based on capabilities for decision making, short-time memory, selected communication skills, and ability to eat independently. Furthermore, we included the following "single" items of the interRAI HC: (a) "Cognitive skills for daily decision making" the response mode of which comprises six categories (from independent to no discernable consciousness); (b) Memory / recall ability composed of three functions (shortterm memory, procedural memory, and situational memory); (c) Presence of the diagnosis "Alzheimer" and/or "Dementia - other than Alzheimer".

The capability for coping in everyday life was measured by three items: managing of finances, managing of medication, and utilization of the phone over the course of last three days, respectively. All items exist in two forms: on the one hand "Performance" that reflects the level of actual execution of the tasks, and on the other hand, the "Capacity" with a code based on the presumed ability to carry out these activities as independently as possible. Thus, "Performance" reflects the real doing of the client, whereas "Capacity" contains a speculative answer to the question "What could the individual do?" Together with five other items, these items are used for calculation of IADL-scales (Morris et al., 1999). We excluded the other five items from our analyses since they contain activities which are not equally demanding for people with cognitive problems, e.g., light housework (dusting, washing dishes etc.). Some items are not common for all clients, e. g., using stairs. In our sample, this was the case in $44 \%$ of the participants who have lifts at their disposal or live on the ground floor. Of the clients, $44.5 \%$ do not use public transportation because "they do not need it." Every fifth 
Running Head: SOCIAL HEALTH AND COGNITIVE PERFORMANCE 6

person does not need to go shopping, probably because the deliveries of groceries and other goods belong to the home care service.

We measured the fulfilment of social obligations by the frequency of (a) participation in social activities of long-standing interest; (b) visits with long-standing social relations of family; (c) communication on phone or email interaction with friends or relatives.

\section{Data Analysis}

We used the Statistical Software for Social Sciences (SPSS) Version 23 to calculate sample characteristics and frequencies of cognitive impairments and memory problems. Using the SPSS General Linear Model we examined the independent and joint contributions of cognitive performance and memory problems to the capacity for and performance in various IADLs as well as to the frequency of different types of social interactions.

\section{Results}

\section{Descriptives}

Table 1 shows an overview of the study population at baseline and at the first reassessment realized six months after. It has to be stressed that not the general population of older adults was examined here, but a sample nearly representative of the "typical users" of community home care services in Belgium, Finland, Germany, Iceland, Italy, and the Netherlands. The age of the clients amounted to 83 years, on average; about two thirds were female. The large majority of the clients were widowed, and about $30 \%$ married.

\section{Insert table 1 about here}

Table 2 summarizes all measurements of cognitive status that we considered in the analyses. More than $50 \%$ of the clients exhibited intact cognitive performance (measured by the CPS-scale). About $30 \%$ belong to the category of mildly to moderately impaired persons 


\section{Running Head: SOCIAL HEALTH AND COGNITIVE PERFORMANCE 7}

that are the focus of our interest in this manuscript. Only $12.7 \%$ were much more cognitively impaired at baseline, slightly more at the first reassessment. Significant changes in cognitive performance will be presented in a subsequent paper.

We calculated the average CPS score of the total sample as $M=1.54(S D=1.78)$ at baseline; this score lies between the "borderline intact" and "mildly impaired" status. The median $=1.0$ indicates that cognitive abilities are either intact or not very limited in half of the clients. We found striking differences between countries. The majority of the clients in the Netherlands ( $61 \%$ ), but only $22 \%$ of the Italians were cognitively intact. Of the Italian clients, 42.5\% exhibited a cognitive impairment "worse than moderate." In Finland, $31.8 \%$ of persons were "cognitively intact"; $20 \%$ were rated as "borderline intact", and $44.4 \%$ were mildly to moderately cognitively impaired. In the Netherlands, the percentage of "borderline intact" was relatively high $(24.7 \%)$. There, only $13.1 \%$ were mildly to moderately impaired, and only $1.1 \%$ had a score "worse than moderate".

Considering three different functions of memory, we observed that short-time memory problems are a common occurrence. They arise in more than $40 \%$ of our study participants. One third exhibits problems with their procedural memory. This means that they have difficulties to recall all sequences of a process or task. About one quarter of the study population exhibits problems with situational memory. They have difficulties of orientation in (even familiar) space or ambience, and are insecure in recognizing related persons or caregivers.

\section{Insert table 2 about here}

Furthermore, Table 2 shows clients' cognitive skills for everyday decisions, like the selection of appropriate clothes, going out, etc. At baseline, almost half of the clients were independent. $17 \%$ exhibited only minimal impairment of decisions in new or difficult 


\section{Running Head: SOCIAL HEALTH AND COGNITIVE PERFORMANCE 8}

situations. Up to $12 \%$ were moderately impaired, and $11.3 \%$ severely impaired. Twenty-three persons were excluded because they did not show discernable consciousness (they were in the status of coma). $15.8 \%$ had the diagnosis of dementia, $12.4 \%$ the diagnosis of Alzheimer's. The presence of the Diagnoses Alzheimer's and other dementias does not necessarily correspond with impaired cognitive performance (as measured by the CPS-scale). In our sample, a significant portion of people with "intact" cognitive function had Alzheimer or another type of dementia. With regards to Alzheimer's, we found this situation especially in Finland in $6.2 \%$ of all cases, and with regards to other dementias in Germany (12.8\%).

\section{Insert table 3 about here}

We describe how the study participants were able to fulfil three selected obligations in table 3. Approximately, one quarter is independent in managing money, every fifth participant also when practicing self-medication. Phone use seems to be easier for more than two thirds (performance), and $63.5 \%$ possessed the capacity to do it. Correspondingly the proportions of people who need maximal assistance or are fully dependent on help vary.

\section{Insert table 4 about here}

Table 4 shows the performance and capacity for routine activities in the group of individuals whose cognition is mildly to moderately impaired (according to the CPSmeasurement) only. Even at first glance, the differences are huge with regards to management of finances as well as medication. The percentage of persons who can cope with such requirements remained under ten per cent. At the same time, the proportion of people who cannot fulfill these tasks is much higher. In contrast, the use of the phone is much better 


\section{Running Head: SOCIAL HEALTH AND COGNITIVE PERFORMANCE 9}

preserved. Still more than half of clients with moderate to mild impairment are capable, and even independent when performing this task.

Participation in social activities of the total sample is presented in Table 5. The temporal distance to the assessment is an indicator of the frequency of the activities under study. The interaction with confidants or relatives (personally or on the phone, or by email) occurs more frequently than the "general participation in activities", which were realized by about a half of the sample within the last three days before the assessment. Although the percentages in Table 5 seem to be similar to those in Table 4, the participants with mild to moderate cognitive impairment cope rather differently in social situations (Table 5). All differences are highly significant. In particular, there are many people who never have "visits", and there is a lower proportion of clients visiting someone or receiving visits within last three days. These effects are similar with regards to calling or emailing.

Insert table 5 about here

Insert table 6 about here

\section{Determinants of the Degree of Independence in Participants with Varying Levels of}

\section{Cognitive Performance}

Capabilities to handle money, medication, and phone. As mentioned above, we investigated the capabilities for completing these tasks. They do not necessarily reflect how the individuals actually perform, but are to some degree based on speculations of the nursing staff and assessors: Would the client have been able to do it in the last three days? In parallel, we analyzed the real performance in these areas. For both functions, we looked at the influence of the measured cognitive performance expressed by the CPS-score. For these analyses, we applied a general linear model. 


\section{Running Head: SOCIAL HEALTH AND COGNITIVE PERFORMANCE 10}

First, we report on the capability for management of finances, medication, and using the phone; these continuous variables were entered into the model as dependent variables. All three tasks are significantly dependent on cognitive performance (CPS-scale) (controlling for procedural memory: managing finances: $F(2,2314)=60.78, p<.001$; managing medication: $F(2,2328)=81.23, p<.001$; phone use: $F(2,2264)=229.61, p<.001)$. Moreover, we found a significant interaction of the CPS-score with procedural memory as well as with situational memory, the first one influencing the management of finances $(F(2,2314)=7.36, p=.001)$ and the intake of medication $(F(2,2328)=8.70, p<.001)$, the second the management of medication only $(F(2,2327)=3.01, p=.050)$.

Procedural memory alone also has a significant influence on the handling of finances $(F(1,2314)=23.94, p<.001)$. If problems of this memory function occur, the ability to meet this obligation is significantly reduced. Procedural memory or more specifically, the ability to recall the sequences of a process determines the capability for the handling of medication $(F(1,2328)=39.83, p<.001)$, and of the phone $(F(1,2264)=39.66, p<.001)$. However, the capability to fulfill the last mentioned requirement also depends on the situational memory $(F(1,2263)=27.16, p<.001)$. But in principle, cognitive performance (CPS) is the most important prerequisite of the "instrumental capabilities." Its interaction with procedural memory sometimes determines the degree of independence when completing the requirements of handling money and bills, self-medication, and using the phone. The shorttime memory is not at all relevant for fulfilment of these obligations; situational memory only has a limited influence.

Performance in these three tasks. The next step of our analysis was the examination of the influence of memory on the real performance of the home care clients. For this purpose, we also used a general linear model, with the three memory functions as independent variables. 


\section{Running Head: SOCIAL HEALTH AND COGNITIVE PERFORMANCE 11}

For the performance of clients' managing of finances, it is unimportant, if the clients exhibit problems of short-time memory. A different result occurs, if clients have problems with their procedural memory which minimizes the performance for all clients $(F(1,1983)=$ 22.94, $p<.001)$. Interestingly, these problems interfered more, if otherwise cognitively intact persons were considered, but slightly less in mildly and moderately impaired clients, and still less in clients with a severe cognitive impairment $(F(2,1983)=7.33, p=.001)$. Finally, the problems of situational memory (the deficits in "orientation") were equally unimportant for paying bills and credit transfer.

As far as the real self-medication is concerned, it is - according to our analysis - not dependent on problems with short-term memory. Though, procedural memory $(F(1,2109)=$ $39.74, p<.001)$ and situational memory $(F(1,2109)=9.22, p=.002)$ play a role. They reduce the actual execution of this task, however, more in cognitively intact persons, than in mildly or moderately impaired or even in those clients who are severely cognitively impaired.

Looking at the performance in phone use, we did not find that it was affected by shorttime memory problems; only problems with procedural memory $(F(1,2006)=42.58, p<$ $.001)$ and orientation $(F(1,2006)=22.01, p<.001)$ affected this performance significantly. People with disturbance of both are less able to complete this task.

How far are the social interactions of mildly to moderately impaired clients dependent on cognitive performance? Using a general linear model, we examined the influence of the Cognitive Performance Score (CPS) on three items measuring different aspects of social interaction. The analysis shows that all of them are significantly dependent on the cognitive performance (controlling for procedural memory: participation in social events of long-standing interest: $F(2,2148)=21.81, p<.001$; visit with a long-standing social relation or family member: $F(2,2254)=6.75, p=.001$; other interaction with longstanding social relation or family member: $F(2,2184)=59.82, p<.001)$. Social interactions 
Running Head: SOCIAL HEALTH AND COGNITIVE PERFORMANCE 12

(participation, reciprocal visits with relatives and friends, and contact by phone/mail) are less frequent in clients with cognitive impairments compared to clients with intact cognition.

To what extent are the three types of social interaction dependent on memory? We examined the role of "short-term memory", "procedural memory", "and situational memory." The problems of short-term memory neither influence the frequency of "participation", nor that of "visits", nor the interaction on phone/by mail. The problems of procedural memory lead to a reduction of the frequency of visits in all clients, not only of those who are mildly or moderately impaired $(F(1,2254)=10.46, p=.001)$ and of interactions by phone or email $(\mathrm{F}(1,2184)=17.76, \mathrm{p}<.001)$. Together with the CPS in one regression model, problems of procedural memory influence the participation in social activities $(F(2,2148)=5.38, p=$ $.005)$. The problems of situational memory do not significantly affect the "participation in long standing social interests." However, they lead to a reduction of "the frequency of visits" $(F(1,2254)=10.46, p=.001)$. They also affect the interaction on phone/by email negatively $(F(1,2184)=25.29, p<.001)$.

\section{Discussion}

We observed that more than fifty percent of the clients of the home care services included in this study have intact cognitive performance. Thus, it is not surprising that one quarter of the participants are completely independent when managing finances and medication, and more than sixty percent have no problems with the use of the phone. The picture changes substantially when the participants who are mildly to moderately cognitively impaired are considered (approximately $30 \%$ of the sample). However, a far larger number of clients (not only the $9 \%$ who were fully independent) meet the definition of Social Health by Huber and colleagues (2011). About one quarter of them managed finances and medication with limited assistance or some supervision. This becomes even more apparent when the use of the phone is considered; almost eighty percent perform this task relatively independently, 


\section{Running Head: SOCIAL HEALTH AND COGNITIVE PERFORMANCE 13}

namely with supervision and limited assistance. In terms of social participation, it is striking that all clients, and particularly those with mild to moderate cognitive impairment interact mostly with close relatives and friends. Apparently, clients of home care have limited access to or less opportunity for social interactions within a larger social network; this is demonstrated by the $41.1 \%$ or $40 \%$ that never participate in social activities of this kind, even if these activities had been of long standing interest (see Tables 5 and 6). This may be due to the physical function of the clients, but it goes against the concept of participation as defined by the WHO (WHO, 2013).

We observed that cognitive performance clearly determines the ability to manage one's own life and to fulfil various obligations at home and in the community. However, when summarizing our findings with regards to the performance in three activities that may be challenging, we have to conclude, that memory problems do not play a big role. Handling of money, medication, or phones are determined by overall cognitive performance, not by specific memory functions alone. Short-term memory in particularly appears to have little influence on the performance of and capacity in the IADLs as well as on the frequency of social interactions. This could come as a surprise given that the general public tends to hold the opinion that older people with short-term memory problems are completely incompetent. It is plausible that procedural memory plays a relatively big role. Management of money and of medication and phone and other devices necessitate that one knows how this process works. It also makes sense that situational memory leads to a reduction in the frequency of visits because problems in this memory domain refer to issues recognizing people and handling unknown interpersonal situations. In many instances, the effects of specific memory problems depend on overall cognitive performance; for several of the IADLs examined here, they do not play a role above and beyond overall cognitive performance.

\section{Strengths and Limitations}




\section{Running Head: SOCIAL HEALTH AND COGNITIVE PERFORMANCE 14}

One of the main strengths of the study is the study population - cognitively intact and impaired clients of home care services. Few studies on this population exist. But these studies are extremely important because a large number of people with a need for care live at home, not in an institutional facility, and this number will increase even further in the future. The other main strength of the study is the international composition of the sample. A more detailed examination of country differences belongs to the plans of the entire project that aims to reveal all country differences caused by health policies.

The limitations are mostly methodological in nature. Short-term memory is also measured within the CPS scale. This may be one of the reasons why the separate measure of short-term memory - when considered together with cognitive performance as measured by the CPS scale - is relatively unimportant for predicting the performance and capacity for routine activities as well as the frequency of social interactions. Furthermore, a comparison with the general population of older adults was not part of this study.

The concept of "Social Health" (Huber et al., 2011) assumes "a development of successful strategies of coping" by adapting to an illness and learning of management of the own life of individuals affected by impairments and diseases. However, the question arises to what extent this concept applies to the situation of persons, whose mental faculties are progressively deteriorating because - in contrast to younger people who suffer, for instance, from intellectual disabilities - the functions of "adapting" and "learning to cope with the changed capabilities" suffer due to the cognitive regress (Boote et al., 2006; Caffò et al., 2012).

\section{Conclusions}

The concept of "Social Health" has to be examined in relation to those older adults whose cognitive deficits consist of inability to adjust to the progressing disability. Future research has to investigate how far the provision of organized home care and home nursing have a part in it, or how far they are appropriate to guarantee this scope. Our study shows that 


\section{Running Head: SOCIAL HEALTH AND COGNITIVE PERFORMANCE 15}

mild to moderate cognitive limitations do not hinder clients of home care from continuing to cope at least somewhat independently with routine requirements at home and in the community. Importantly, when considering the influence of cognitive function on clients' capacity and performance in these areas, a comprehensive construct of cognitive function (such as the interRAI CPS) has to be applied; specific subdomains, for example, relatively narrow realms of memory seem to have a limited influence when examined on their own. 


\section{Running Head: SOCIAL HEALTH AND COGNITIVE PERFORMANCE 16}

\section{References}

Boote, J.; Lewin, V.; Beverly, C.; Bates, J. (2006): Psychosocial intervention for people with moderate to severe dementia: A systematic review. Clinical Effectiveness in Nursing, 951, e1-e15, doi:10.10.16/j.cein.2006.06.002

Caffò, A. O., De Caro, M.F., Picucci, L., Notarnicola, A., Settanni, A., Livrea, P., Lancioni, G.E., Bosco, A. (2012): Reorientation deficits are associated with amnestic mild cognitive impairment. American Journal of Alzheimer's Disease and Other Dementias, 27(5), 321-30. doi: 10.1177/1533317512452035.

Day, K.; Carreon, D.; Stump, C. (2000): The therapeutic design of environments for people with dementia: A review of the empirical research. The Gerontologist, 40, 4, 397-416

Garms-Homolová, V. (2013): Germany. In: Genet, N.; Boerma, W.; Kroneman, M., Hutchinson, A.; Saltman, R. B. (eds.): Home Care across Europe. Case Studies. Copenhagen: WHO, European Observatory on Health Systems and Policies. Observatory studies series 27, pp $110-118$.

Garms-Homolová, V.; Kardorff, E.v., Theiss, K.; Meschnig, A.; Fuchs. H. (2009): Teilhabe und Selbstbestimmung von Menschen mit Pflegebedarf. Konzepte und Methoden. Frankfurt, Main: Mabuse Verlag, ISBN 978-3-940529-08-4

Garms-Homolová, V., Naidisch, M., Fagerström, C., Lamura, G., Melchiore, M.G., Gulasci, L. \& Hutchison, A. (2012). Clients in Focus. In: Genet, N., Boerma, W., Kroneman, M., Hutchinson, A., Saltman, R.B. (eds.), Home Care across Europe. Current structure and future challenges. Copenhagen: WHO, European Observatory on Health Systems and Policies. Observatory studies series 27 , pp. 55-70

Genet, N., Boerma, W., Kroneman, M., Hutchinson, A., Saltman, R.B. (eds.) (2012): Home Care across Europe. Current structure and future challenges. Copenhagen: WHO, European Observatory on Health Systems and Policies. Observatory studies series 27 


\section{Running Head: SOCIAL HEALTH AND COGNITIVE PERFORMANCE 17}

Hartmeier, S.L., Sloane, P.D.; Guess, H.A.; Kock, G.G.; Michel, C.M. \& Phillips, C. D. (1995): Validation of the Minimum Data Set Cognitive Performance Scale. Agreement with the Mini-Mental State Examination. The Journal of Gerontology, Series B: Biological Sciences and Medical Sciences, 50, M128-M133

Huber, M.; Green, L.; van der Horst, H.; Jadad, A.R.; Kromhout, D.; Leonard, B.; Loring, K., et al. (2011): How should we define health? $B M J$, 343:d4163doi:10.1136/bmj.d4163,1-3

Kruse, A. (2005). Lebensqualität demenzkranker Menschen. Zeitschrift für Medizinische Ethik, 51, 41-58.

Morris, J. N.; Fries, B.E.; Mehr, D. R.; Hawes, C; Phillips, C.; Mor, V.; et al (1994): MDS Cognitive Performance Scale. Journal of Gerontology, Series A: Medical Sciences, 49, M174-M182

Morris, J. N.; Fries, B.E.; Morris, S. A. (1999): Scaling ADLs within the MDS. The Journal of Gerontology. Series A, Biological Sciences and Medical Sciences, 54, M546-M553

Morris, J.N.; Howard, E.P.; Steel, K.; Perlman, C.; Fries, B.E.; Garms-Homolová , V.; Henrard, J.C.; Hirdes, J.P.; Ljunggren, G.; Gray, L.; Szczerbinska, K. (2015):Updating the Cognitive Performance Scale. Journal of Geriatric Psychiatry and Neurology, 1-9, DOI:10.1177/0891988715598231, jgpn.sagepub.com

World Health Organization (2013): How to use the ICF: A practical manual for using the International Classification of Functioning, Disability and Health (ICF). Exposure draft for comment. October 2013. Geneva: WHO

World Health Organization (2001): ICF: International Classification of Functioning, Disability and Health (ICF), 2.Fifty-fourth World health Assembly. WHA54.21. International classification of functioning, disability, and health. Ninth plenary meeting 22.May 2001, A54/VR/9, WHO, Geneva, 
Table 1: Description of the population under study ${ }^{1}$

\begin{tabular}{|c|c|c|c|c|}
\hline & \multicolumn{2}{|c|}{ Baseline } & \multicolumn{2}{|c|}{ T1-First Reassessment } \\
\hline $\begin{array}{l}\text { Average age in } \\
\text { years (SD) }\end{array}$ & $83.44(7.2)$ & & $83.91(7.28)$ & \\
\hline Gender & Number & Percent & Number & Percent \\
\hline male & 742 & 31.0 & 752 & 31.4 \\
\hline female & 1647 & 68.9 & 1643 & 68.6 \\
\hline Marital status $^{2}$ & Number & Percent & Number & Percent \\
\hline Never married & 215 & 9.7 & 217 & 9.9 \\
\hline Married/partner & 658 & 29.8 & 664 & 27.7 \\
\hline widowed & 1178 & 53.2 & 1267 & 52.8 \\
\hline Divorced/separated & 162 & 7.3 & 178 & 7.5 \\
\hline
\end{tabular}

\footnotetext{
${ }^{1}$ Missings are not presented in the table.
}

${ }^{2} 185$ no answer 


\footnotetext{
${ }^{3}$ The CPS scale has seven categories (from $0=$ intact to $6=$ very sever impairment). The "intact" and "borderline intact" categories were combined. Similarly "mild" and "moderate impairment" were combined. The last three categories build together "worse than moderate" impairment. Reason for these changes: low numbers in some categories.

${ }^{4}$ Clients without discernable consciousness were skipped here.

${ }^{5}$ The category no discernable consciousness was skipped here.

${ }^{6}$ The diagnoses were assessed by a "pick list", mainly according to the clients' record. It is possible that a

reliable differential diagnosis was available in all cases.
}

Table 2: Cognitive status of Home Care Clients under study

\begin{tabular}{|c|c|c|}
\hline $\begin{array}{c}\text { Cognitive performance (according to } \\
\text { CPS-score }\end{array}$ & $\begin{array}{l}\mathbf{T}_{\mathbf{0}} \\
\mathbf{\%}\end{array}$ & $\begin{array}{c}\mathbf{T}_{\mathbf{1}} \\
\mathbf{\%}\end{array}$ \\
\hline Intact to Borderline Intact & 57.2 & 53.8 \\
\hline Mild to moderate impairment & 30.1 & 31.9 \\
\hline Worse than moderate & 12.7 & 14.3 \\
\hline Memory $^{4}$ & & 41.9 \\
\hline Problems with short-time memory $^{\text {Problems with procedural memory }}$ & 41.9 & 32.3 \\
\hline Problems with situational memory $^{\text {Cognitive skills for daily decision }}$ \\
making
\end{tabular}


Table 3: Performance in and Capacity for routine activities at home or community ${ }^{7}$ (Baseline, total sample)

\begin{tabular}{|c|c|c|c|c|c|c|}
\hline & \multicolumn{2}{|c|}{$\begin{array}{c}\text { Managing finances } \\
(\%)\end{array}$} & $\begin{array}{l}\text { Managing medication } \\
(\%)\end{array}$ & \multicolumn{2}{c|}{ Phone use (\%) } \\
\cline { 2 - 7 } & $\begin{array}{c}\text { Perform } \\
\text { ance }\end{array}$ & Capacity & $\begin{array}{c}\text { Performa } \\
\text { nce }\end{array}$ & Capacity & $\begin{array}{c}\text { Performa } \\
\text { nce }\end{array}$ & Capacity \\
\hline Independent & 25.1 & 25.0 & 21.7 & 22.7 & 68.4 & 63.5 \\
\hline $\begin{array}{c}\text { Setup help or } \\
\text { supervision }\end{array}$ & 6.9 & 8.5 & 16.9 & 16.4 & 9.8 & 10.5 \\
\hline $\begin{array}{c}\text { Limited } \\
\text { assistance }\end{array}$ & 7.9 & 7.1 & 7.2 & 7.8 & 3.2 & 3.1 \\
\hline $\begin{array}{c}\text { Extensive } \\
\text { assistance }\end{array}$ & 5.4 & 6.2 & 7.7 & 7.4 & 2.4 & 2.9 \\
\hline $\begin{array}{c}\text { Maximal } \\
\text { assistance to total } \\
\text { dependence }\end{array}$ & 54.7 & 53.1 & 46.9 & 45.9 & 16.0 & 20.1 \\
\hline
\end{tabular}

\footnotetext{
${ }^{7}$ The second and last categories were combined since the last categories can not be considered as "relatively independent fulfillment of requirements.
} 
Table 4: Performance in and Capacity for routine activities in mildly to moderately impaired clients (Baseline)

\begin{tabular}{|c|c|c|c|c|c|c|}
\hline \multicolumn{2}{|c|}{} & \multicolumn{2}{|c|}{$\begin{array}{c}\text { Managing finances } \\
(\%)\end{array}$} & $\begin{array}{c}\text { Managing medication } \\
\text { (\%) }\end{array}$ & \multicolumn{2}{c|}{ Phone use (\%) } \\
\cline { 2 - 7 } & $\begin{array}{c}\text { Performanc } \\
\mathbf{e}^{\mathbf{8}}\end{array}$ & $\begin{array}{c}\text { Capacit } \\
\mathbf{9}\end{array}$ & $\begin{array}{c}\text { Performanc } \\
\mathbf{e}^{\mathbf{1 0}}\end{array}$ & $\begin{array}{c}\text { Capacity } \\
\mathbf{1 1}\end{array}$ & $\begin{array}{c}\text { Performanc } \\
\mathbf{e}^{\mathbf{1 2}}\end{array}$ & $\begin{array}{c}\text { Capacity } \\
\mathbf{1 3}\end{array}$ \\
\hline $\begin{array}{c}\text { Independe } \\
\text { nt }\end{array}$ & 9.0 & 8.3 & 6.8 & 7.2 & 62.4 & 52.8 \\
\hline $\begin{array}{c}\text { Setup help } \\
\text { or } \\
\text { supervisio } \\
\text { n }\end{array}$ & 7.8 & 8.1 & 15.6 & 16.1 & 15.7 & 15.4 \\
\hline $\begin{array}{c}\text { Limited } \\
\text { assistance }\end{array}$ & 8.0 & 7.1 & 6.4 & 7.6 & 6.4 & 5.3 \\
\hline $\begin{array}{c}\text { Extensive } \\
\text { assistance }\end{array}$ & 6.6 & 6.4 & 10.9 & 9.8 & 2.8 & 3.9 \\
\hline $\begin{array}{c}\text { Maximal } \\
\text { assistance } \\
\text { to total } \\
\text { dependenc } \\
\text { e }\end{array}$ & 68.6 & 70.1 & 60.3 & 59.2 & 12.6 & 22.7 \\
\hline
\end{tabular}

\footnotetext{
${ }^{8}$ Significantly different from the total sample; $X^{2}=493.805, \mathrm{df}=12 ; \mathrm{p}=.000$;

${ }^{9}$ Significantly different from the total sample; $X^{2}=623.825, \mathrm{df}=12 ; \mathrm{p}=.000$;

${ }^{10}$ Significantly different from the total sample; $X^{2}=670.802, \mathrm{df}=12 ; \mathrm{p}=.000$

${ }^{11}$ Significantly different from the total sample; $X^{2}=760.496, d f=12 ; p=.000$

${ }^{12}$ Significantly different from the total sample; $X^{2}=853.324, \mathrm{df}=10 ; \mathrm{p}=.000$

${ }^{13}$ Significantly different from the total sample; $X^{2}=968.108, d f=12 ; p=.000$
} 
Table 5: Frequency of Social Interaction of Home Care Clients under study (Baseline)

\begin{tabular}{|c|c|c|c|}
\hline & $\begin{array}{l}\text { Participation in social } \\
\text { activities of long- } \\
\text { standing interests (\%) }\end{array}$ & $\begin{array}{l}\text { Visits with long- } \\
\text { standing social } \\
\text { relations/family (\%) }\end{array}$ & $\begin{array}{l}\text { Interaction by } \\
\text { phone/email with } \\
\text { long-standing social } \\
\text { relations/family (\%) }\end{array}$ \\
\hline never & 41.1 & 17.2 & 24.6 \\
\hline >30 days ago & 15.7 & 6.3 & 6.0 \\
\hline 8 to 30 days ago & 10.0 & 11.0 & 6.8 \\
\hline 4 to 7 days ago & 10.0 & 17.6 & 14.0 \\
\hline In last 3 days & 23.2 & 48.0 & 48.5 \\
\hline
\end{tabular}


Table 6: Frequency of Social Interaction in mildly to moderately impaired clients (Baseline)

\begin{tabular}{|c|c|c|c|}
\hline & $\begin{array}{l}\text { Participation in social } \\
\text { activities of long- } \\
\text { standing interests } \\
(\mathbf{\%})^{\mathbf{1 4}}\end{array}$ & $\begin{array}{l}\text { Visits with long- } \\
\text { standing social } \\
\text { relations/family } \\
(\mathbf{\%})\end{array}$ & $\begin{array}{l}\text { Interaction by } \\
\text { phone/email with } \\
\text { long-standing social } \\
\text { relations/family } \\
\mathbf{( \% )}\end{array}$ \\
\hline never & 40.0 & 21.2 & 27.8 \\
\hline >30 days ago & 15.7 & 8.4 & 8.1 \\
\hline 8 to 30 days ago & 10.6 & 10.8 & 8.0 \\
\hline 4 to 7 days ago & 11.5 & 17.5 & 14.7 \\
\hline In last 3 days & 22.2 & 42.2 & 41.3 \\
\hline
\end{tabular}

\footnotetext{
${ }^{14} \mathrm{X}^{2}=108.261, \mathrm{df}=8, \mathrm{p}=.000$;

${ }^{15} \mathrm{X}^{2}=74.033, \mathrm{df}=8, \mathrm{p}=.000$;

${ }^{16} \mathrm{X}^{2}=434.800, \mathrm{df}=8 ; \mathrm{p}=.000$;
} 